\title{
Selling issues with solutions: Igniting social intrapreneurship in for-profit organizations
}

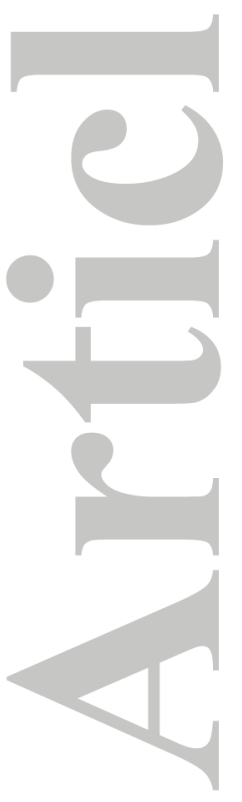

\section{Elisa Alt}

Anglia Ruskin University

Lord Ashcroft International Business School

East Road, Cambridge, CB1 1PT, UK

Office: +44 1245493131 ext. 5039

Email: elisa.alt@anglia.ac.uk

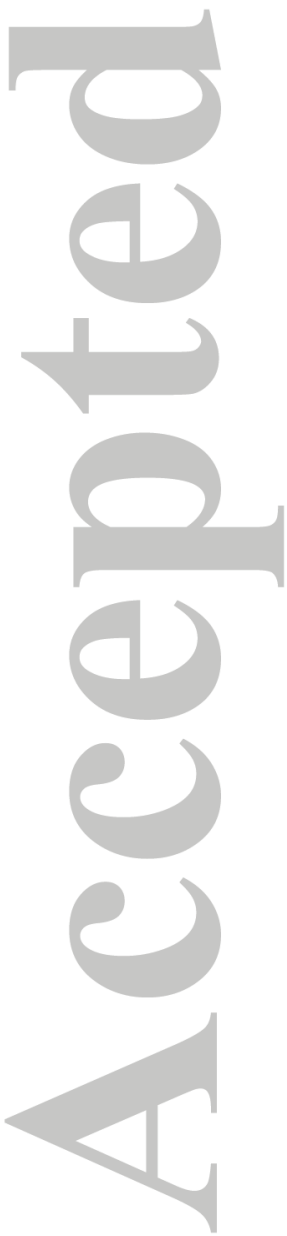

\author{
JuSTIN B. Craig \\ Northwestern University \\ Kellogg Center for Family Enterprises \\ 2001 Sheridan Rd, Evanston, IL 60208, USA \\ Office: +18474677855 \\ Email: justin.craig@kellogg.northwestern.edu
}

This article has been accepted for publication and undergone full peer review but has not been through the copyediting, typesetting, pagination and proofreading process which may lead to differences between this version and the Version of Record. Please cite this article as an 'Accepted Article', doi: 10.1111/joms.12200 


\section{Selling issues with solutions: Igniting social intrapreneurship in for-profit organizations}

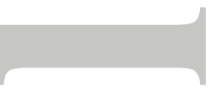

\section{ABSTRACT}

We offer an explanation of the issue selling process when issues deviate from the dominant logic of organizations. Our main objective is to articulate the multiple ways in which socially oriented innovations can be legitimated in for-profit organizations through the work of bottomup change agents, also known as social intrapreneurs. To unpack this multiplicity, we draw on both institutional theory and the framing perspective in social movements. Specifically, we propose how sellers may advance social issues with solutions by drawing on the logic composite of both organizations and selling targets. By providing an account of the social issue selling process in for-profit organizations, we consider how the nature of an issue shapes selling efforts when it diverges from the dominant logic, and we shed light on how the content choices of sellers relate to the meaning systems of organizations and targets.

\section{Keywords:}

Framing tasks; institutional logics; issue selling; legitimacy judgments; social intrapreneurship; vocabularies

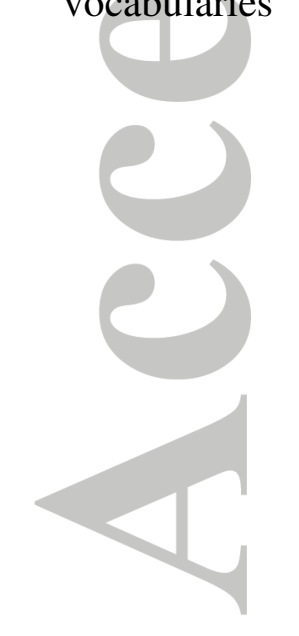




\section{Selling issues with solutions: Igniting social intrapreneurship in for-profit organizations}

\section{INTRODUCTION}

Research in issue selling, which is defined as “individuals' behaviors that are directed toward affecting others' attention to and understanding of issues" within firms (Dutton and Ashford, 1993, p. 398), shows that selling involves complex decisions for change agents (Dutton et al., 2001). First, sellers have to decide the content of selling: whether it is better to sell an issue with a solution or in more abstract terms; whether to tie the issue to other concerns; how to package or frame the issue. Second, sellers must determine how to perform selling: whom they will target and involve; the level of formality of the selling initiative; the best timing. Each of these decisions may influence the likelihood of selling success, highlighting the importance of the knowledge individuals accumulate during the preparation stages of issue selling (Dutton et al., 2001). Yet selling tactics, and consequently the knowledge sellers gather, may shift subject to the type of issue being sold (Piderit and Ashford, 2003).

Researchers of social issues in management (Andersson and Bateman, 2000; Bansal, 2003; Howard-Grenville, 2007; Sonenshein, 2006, 2012, 2014) have fruitfully explored this line of inquiry, linking knowledge of organizational values and targets to both selling tactics and selling success. However, the contributions of this previous research are limited in two ways. First, previous studies have conflated the way in which sellers craft discourse about issues with the way sellers craft solutions (e.g., Bansal, 2003). Yet, many social issue selling initiatives fail because of the lack of a viable solution (Bansal, 2003; Howard-Grenville, 2007), showing the importance of theorizing on how solutions may be crafted to effectively promote selling success. Second, although prior studies have shown that sellers can justify social issues on both instrumental and normative grounds (Andersson and Bateman, 2000; Bansal, 2003; Sonenshein, 
2006), previous work is inconclusive regarding when doing so can enhance the likelihood of selling success. Targets and organizations respond to issues independently (Bansal, 2003) and, as such, understanding how to reconcile knowledge on both meaning systems is essential to improve explanations of successful issue selling in for-profit organizations.

In this paper, we make the case that general explanations of issue selling success - and of social issue selling, specifically_can be enhanced through a renewed focus on sellers' content choices and how these relate to the organizational context and selling targets. Marrying the selling process with institutional logics (Friedland and Alford, 1991) and the framing perspective in social movements (Benford and Snow, 2000; Snow et al., 1986), we offer an explanation of issue selling that articulates the multiple ways in which socially oriented innovations can be legitimated in for-profit organizations through the work of bottom-up change agents.

Change agents working at the intersections of sustainability, ethics, and entrepreneurship within organizations are increasingly challenging the dominance of the commercial logic in forprofit organizations. These individuals, also known as 'social intrapreneurs' (Davis and White, 2015; Grayson et al., 2014; Net Impact, 2009; SustainAbility, 2008), work to advance solutions to social issues that may range from 'not-for-loss' to market penetration in bottom-of-thepyramid markets, showing in practice the multiple ways in which sellers can work with context and target signals to advance social innovations.

We argue that an institutional logic perspective enriches explanations of social issue selling by revealing how social and commercial meanings can have different levels of compatibility (Besharov and Smith, 2014), even in contexts dominated by commercial objectives, as in for-profit organizations. Likewise, we suggest that the framing perspective in social movements illuminates issue selling as a process of intra-organizational mobilization 
(Scully and Segal, 2002), recasting selling as a conversation with targets (Cornelissen and Werner, 2014), and expanding the work of sellers to consider the craft of solutions. Building on both perspectives, we offer nuance to the understanding of context and target signals in social issue selling, and suggest how successful selling can emerge from narratives that tap into broader discourses and targets' interests (Lefsrud and Jennings, 2014; Martens et al., 2007).

We begin by reviewing how issues and solutions have been defined and sold in the literature, to show that more attention to solutions is necessary to improve our understanding of how sellers can craft successful social issue selling tactics. Next, we examine how the organizational context and selling targets have been shown to influence either the tactics of sellers or selling success, and discuss the limitations of current approaches. As an alternative, we offer that attention to the institutional logics enacted in organizations and by targets can enhance the knowledge of sellers and, consequently, their tactical decisions. We then explain how the framing perspective in social movements can enrich explanations of the work of social issue sellers, making the case for a more interactive view of the issue selling process. We follow with a set of propositions that detail how social issue selling initiatives can be legitimated in for-profit organizations, and present a typology of four ideal selling approaches. We conclude with a discussion of the implications of our framework, along with an agenda for future research.

\section{THE WORK OF ISSUE SELLERS}

\section{Issues and solutions defined}

A key decision for issue sellers is whether to sell an issue alone or with a solution, which will likely depend on the type of issue in question (Dutton and Ashford, 1993). As such, it is important to examine how issues in general, and social issues specifically, have been defined in the literature. Traditionally, issue selling researchers (e.g., Bansal, 2003; Dutton and Ashford, 
1993) have adopted Ansoff's definition of strategic issue as “a forthcoming development, either inside or outside of the organization, which is likely to have an important impact on the ability of the enterprise to meet its objectives" (1980, p. 133). In contrast, social issues serve society's interests and improve social welfare (Sonenshein, 2006), carrying "important implications for social change" (Sonenshein, 2012, p. 4), which "can benefit the greater good beyond wealth maximization, such as healthcare, poverty, or the natural environment" (Sonenshein, 2014, p. 3).

By juxtaposing the above definitions, we can observe that a social issue will not always have direct impact on the firm's ability to meet its objectives. If we conceive social issues as stakeholder issues, as claimed by stakeholders themselves or internal social change agents (Sonenshein, 2014), such issues can either affect or be affected by the firm (Bundy et al., 2013; Freeman, 1984). Stated differently, social issues may become relevant for organizations either (1) because they impact firms' objectives, or (2) because firms can help in resolving such issues. These two factors, as we will argue below, highlight the importance of selling social issues with solutions, or social innovations. A social innovation can be formally defined as "the generation and implementation of new social service ideas for solving social problems manifested at either the product or process level or the social system level" (Weerawardena and Mort, 2012, p. 93). We propose that when internal change agents sell social issues with solutions, they are selling social innovations, and for the purpose of this paper we use both terms interchangeably. In this context, selling initiatives can be understood as new plans to act (De Clercq et al., 2011) and help solve a social issue.

\section{Selling issues vs. issues with solutions}

In their seminal work, Dutton and Ashford (1993) proposed that individuals are more likely to initiate issue selling when they can identify a solution to attach to the issue. Yet the 
authors distinguished issue selling from project and innovation championing (Burgelman, 1983; Howell and Higgins, 1990) on the basis that championing involves advancing concrete solutions, whereas selling involves abstract issues. This distinction, however, has not always been made in subsequent empirical studies of issue selling.

For example, studies of individuals selling environmental issues in multiple industries have shown that issues were sold with solutions (Andersson and Bateman, 2000; Bansal, 2003; Howard-Grenville, 2007). In another example, Pandza (2011) showed how groups of sellers focused on potential solutions when selling operational excellence issues in a pharmaceutical company. Other studies have found a mix of preferences among individuals for selling issues with or without solutions, in both a telecommunications company and a not-for-profit hospital (Dutton et al., 1997; Dutton et al., 2001). In contrast, studies examining gender-equity issues with samples of working women in multiple organizations (Ashford et al., 1998; Dutton et al., 2002; Piderit and Ashford, 2003) make no mention of solutions. However, it is not possible to establish whether solutions were not addressed due to participants' preferences or to study design, which in these cases relied on generic case descriptions of issues, and examined individuals' willingness to sell issues (Ashford et al. 1998; Dutton et al. 2002), or clusters of upward influence tactics (Piderit and Ashford, 2003).

Overall, this literature, though not vast, shows that individuals tend to prefer selling issues with solutions. Dutton et al.'s (1997) study illustrates this preference, as selling issues with solutions was an important part of sellers' recipe for success at a telecommunications company. A cautionary note, however, comes from Howard-Grenville's (2007) study of issue sellers at Chipco, a microprocessor manufacturer: if targets do not see a problem, there is little 
value in advancing a solution. Selling moves, she argues, should demonstrate how sellers and targets depend on one another to solve problems.

Yet we suggest that a different dimension of this argument reveals how solutions may in fact help shape conversations around problems or issues. At the heart of Howard-Grenville's (2007) observation is the idea that what constitutes a problem for society may not necessarily represent a problem for an organization. Specifically, she calls attention to the goals met by solutions advanced by sellers. In her study, sellers of environmental issues were successful to the extent that they proposed solutions with clear commercial and technical goals. Bansal (2003) identified a similar pattern in a study of environmental issue selling in two manufacturing companies. In both organizations, sellers were successful in advancing many environmental issues, except those with solutions that were not deemed economically viable.

Building on these findings, we argue that theorizing on how solutions link to context is an important avenue for enhancing our understanding of successful issue selling. Social problem theory suggests that "solutions produce problems by providing the framework within which those problems can be stated" (Spector and Kitsuse, 1987, p. 84). This notion, though encapsulated in the original issue selling framework (Dutton and Ashford, 1993), has received little attention in subsequent studies. Most studies seem to conflate issues with solutions, overlooking both how sellers shape solutions in light of their contexts, and how solutions enable selling success.

As we will argue, if solutions are to be part of a recipe for issue selling success (Dutton et al., 1997), these solutions should connect to the meaning systems of organizations and targets. Such solutions need not be assertive (Howard-Grenville, 2007), nor definitive. Crafting a tentative solution may take more time than selling an abstract issue (Dutton and Ashford, 1993), 
but may help contextualize the issue as it links to the goals or capabilities of the firm. Given the complexity and long-term nature of social issues, tentative solutions may be particularly important in enhancing targets' perceptions of organizational capability to address such issues (Dutton and Duncan, 1987). Graham Simpson, for example, linked the challenge of deaths due to simple diseases in rural Africa to GSK's capabilities, by proposing the development of cheap, easy diagnostic tests (Simpson, 2012). In another example, Sacha Carina proposed to link the mobile phone locations of slum business owners to TNT's global logistics network, enabling the creation of geocode-based addresses that overcome the challenges associated with the lack of formal addresses in slums (van Ginhoven, 2013). In both examples, the initial tentative solutions received support and continued to be developed collectively with both internal and external stakeholders. Hence, we propose:

\section{Proposition 1: Contextualizing social issues through tentative solutions will likely} facilitate social issue selling initiatives.

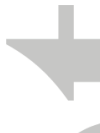
(1)

If solutions hold the potential to represent influential narratives of social issue selling, it is necessary to understand how sellers can integrate their ideas into broader discourses (Martens et al., 2007). Next, we examine the contributions and limitations of current understanding on the roles of the organizational context and targets in the selling process.

\section{CONTEXT AND TARGET SIGNALS IN SOCIAL ISSUE SELLING}

Understanding and interpreting the organizational context and targets of selling initiatives is a key aspect of the work of issue sellers. Successful sellers and champions have high levels of normative, strategic, and relational knowledge (Dutton et al., 2001; Howell and Boies, 2004), 
and express that knowledge through selling moves that improve their ability to influence organizations to address issues (Howard-Grenville, 2007). Social issues, which are often 'wicked' problems and not necessarily linked to the objectives of for-profit organizations, may thus challenge sellers' interpretations of contextual and target signals for selling.

\section{Understanding the organizational context for social issue selling}

One way in which sellers sell social issues in for-profit organizations is by shaping discourse around issues, or public justifications for issue adoption, in light of the values organizations emphasize (Bansal, 2003; Sonenshein, 2006). Accordingly, studies examining environmental issue selling found that success depended on the strength of organizations' environmental paradigm (Andersson and Bateman, 2000), or the congruence of the issues with organizational values (Bansal, 2003).

Bansal's (2003) study is particularly illuminating in this regard. Specifically, she demonstrated that framing how issues benefited organizations was not the only way of generating positive organizational responses, as successful sellers could also appeal to norms and values if their organizations displayed commitment to the environment or society. Yet she also emphasized that "some values had greater priority or importance than others, and fit with those values was more relevant than with less important values" (Bansal, 2003, p. 521). Hence, sellers in her study could advance issues on moral grounds, but only succeeded to the extent that issues could also be aligned with economic values.

We suggest that two limitations characterize our current understanding of how context influences social issue selling. First, although the extant literature offers useful insights into how context influences the discourse of sellers around issues (Bansal, 2003; Sonenshein, 2006), the question of how sellers can craft solutions that connect to the meaning systems of organizations 
remains unanswered. As previously argued, this is important because solutions can facilitate the work of issue sellers by contextualizing the link between social issues and firms' capabilities.

Second, the conceptualization of context in terms of values implies that there is a hierarchy among values (Rokeach, 1973). As economic values prevail in for-profit organizations, the notion of values limits explanations of organizations adopting solutions to social issues that have little congruence with economic values. As we will argue below, a focus on logics (as opposed to values) allows for a more nuanced and heterogeneous understanding of the organizational meaning system, where meanings can be observed not only in terms of their centrality (or hierarchy), but also in terms of their compatibility (Besharov and Smith, 2014).

\section{Institutional logics in social issue selling}

At the field level, a logic is defined as "a set of material practices and symbolic constructions-which constitutes its organizing principles and which is available to organizations and individuals to elaborate" (Friedland and Alford, 1991, p. 248). The elaboration of organizing principles by individuals and organizations may, in turn, lead to the construction of organizational logics. Organizations filter institutional prescriptions through various attributes, such as their identity, ownership, governance, structure, and their position within a field (Greenwood et al., 2011). Because these attributes are heterogeneous among organizations, there is variation in how logics prescribed at the institutional level are elaborated at the organizational level. Thus, for each organization this filtering process results in an organizational logic (Crilly and Sloan, 2012; Helms et al., 2012; Spicer and Sewell, 2010), which can be understood as “a composite expression of a range of institutional logics localized in time and space" (Spicer and Sewell, 2010, p. 918). As an alternative construct through which to consider the context for selling social issues, logics contrast not only with values but also with culture (Dutton et al., 
1997, Dutton et al., 2002; Howard-Grenville and Hoffman, 2003). Next, to unpack our

arguments, we highlight the differences among these three conceptions of context, as well as the resulting implications for our theory development.

The notions of culture and logics are highly interrelated. In a recent dialogue between institutional theory and organizational culture scholars, Schultz and Hinings (2012, p. 108) suggest that "organizational cultures embody and challenge prevailing and new institutional logics... [and] institutional logics embody and challenge prevailing organizational cultures". In this paper, we subscribe to the idea that logics provide 'raw cultural material' (Jones and LivneTarandach, 2008) to individuals and organizations, as aligned with research examining how institutional logics are enacted at the organizational level (e.g., Almandoz, 2012, 2014; Besharov and Smith, 2014; Mair et al., 2015; Pache and Santos, 2013; Smets et al., 2015). In doing that, we do not see the operationalization of logics at the organizational level as substitutive of —or equivalent to-organizational culture. Instead, we see logics as elements of idiosyncratic internal cultures. The notion of logics as cultural materials, as McPherson and Sauder (2013, p. 168) suggest, “has an obvious affinity to Swidler's (1986) cultural toolkit approach”. Although we acknowledge that culture shapes action, and that actors use culture to promote change (Swidler, 1986), we suggest that attention to logics as raw elements of cultures can enable meaningful comparisons of social issue selling across for-profit organizations, and enhance our understanding of how social innovation unfolds in such contexts.

We also argue that a focus on logics enables observations of variations of the selling process that are not captured by the values perspective. As we discussed in earlier coverage of Bansal's (2003) study, implicit in the view that organizations will respond to issues that have congruence with organizational values is a hierarchy among existing values (Rokeach, 1973). 
This notion implies that social issues are, to varying degrees, inherently illegitimate in for-profit organizations due to strong profit motives or shareholder primacy (Sonenshein, 2014). Although the illegitimacy of social issues could be justified on the basis of a dominant commercial logic,

we argue that from a logics perspective, actions that are peripheral to for-profit organizations are conceptually different from those considered inappropriate or undesirable (i.e., illegitimate).

Specifically, we suggest that the notion of hierarchy falls short in capturing all relevant dimensions that may explain how different logics can coexist within an organization.

Besharov and Smith (2014) propose that in order to understand how two or more logics are enacted in organizations, it is useful to observe the dimensions of centrality and compatibility. Centrality refers to the degree to which multiple logics "manifest in core features that are central to organizational functioning", whereas compatibility refers to the degree to which logics "imply consistent organizational actions" (Besharov and Smith, 2014, p. 365). According to this rationale, centrality is high when two or more logics are central to a given organization, and low when a single logic guides the organizational core. Similarly, compatibility is high when an organization enacts two or more logics such that one reinforces the prescriptions of the other, and low when the organization adopts contradictory prescriptions from both logics. Hence, we argue that the notion of compatibility between different logics enables researchers to capture variations in the social issue selling process that the notion of centrality, or subordination to dominant values, would not reveal on its own. For the purpose of our paper, we consider how different levels of compatibility between a core commercial logic and a peripheral social welfare logic may influence the social issue selling process in for-profit organizations. A social welfare logic guides activities that benefit society and the natural environment by improving social conditions, addressing social needs, and relieving suffering (Lee and 
Battilana, 2013; Pache and Santos, 2013; Smith et al., 2013). Specifically, it promotes initiatives that "improve the well-being of communities on local and global levels in such areas as health, race relations, the environment, or economic development" (Bies et al. 2007, p. 788), and hence underpins the work of social issue sellers. In the context of for-profit organizations, it contrasts with the commercial logic of "profit, efficiency, and operational effectiveness" (Smith et al., 2013, p. 417) because it promotes goals that go beyond wealth maximization (Sonenshein, 2014).

Hence, despite the centrality of the commercial logic in for-profit organizations, a social welfare logic can also be present in such contexts, either reinforcing profit-oriented goals (high compatibility) or prescribing independent goals (low compatibility). Nestlé's work in building a milk factory in the Indian district of Moga exemplifies a case of high compatibility between the commercial and the social welfare logics. Nestlé needed a large supply of quality milk from small dairy farmers, who lived in conditions of severe poverty that limited the viability of their business. In this context the company established a series of initiatives around training, logistics, and technology adoption, which resulted in substantial improvements in Moga's standard of living (Porter and Kramer, 2006). In this case, compatibility is high because the social welfare logic that promoted the enhancement of living conditions in Moga was consistent with Nestlé's need of establishing a competitive business, thus enhancing the goals of its commercial logic (Besharov and Smith, 2014). In contrast, Daimler's cooperation with competitors and environmentally friendly technology companies is a case of low compatibility between the commercial and the social welfare logics. Jointly with Volkswagen, the company established collaborations with Choren industries to develop biofuels, and jointly with Ford, it partnered with Ballard to develop fuel cell technology (Pinkse and Kolk, 2010). In this case, compatibility 
is low because the social welfare logic that promoted the investment in environmentally efficient technologies required cooperation with close competitors, meaning that Daimler would not directly obtain competitive advantages from such initiatives, or contribute to the goals of a shortterm commercial logic.

In summary, by accounting for the different degrees to which the commercial and social welfare logics may be compatible in for-profit organizations, we can understand when selling success will depend on whether the solutions advanced by sellers reinforce economic values. This understanding, however, is incomplete without attention to how targets shape the efforts of social issue sellers.

\section{Understanding targets for social issue selling}

Relational knowledge, which involves "both a sense of whom to involve and a sense of how to motivate their involvement" (Dutton et al., 2001, p. 727), is a critical factor for issue sellers. Studies in environmental issue selling, for example, suggest that successful sellers are skilled in adjusting and appealing to the knowledge, values, and beliefs of targets (Bansal, 2003;

Gattiker et al., 2014; Howard-Grenville, 2007). More specifically, Sonenshein (2006) considered how the power of targets shaped public justifications of social issues, suggesting that sellers use economic language to compensate for lack of power. However, we argue that two factors limit our understanding of how sellers and targets interact in social issue selling.

First, the notion of power does not fully capture the target's meaning system and its potential effect on the public justifications of sellers. Bansal's (2003) findings are again particularly relevant to our argument. By identifying that responses to issues could be either individual or organizational, she pointed to "the opportunity for issue sellers to use issue characteristics that generate concern among colleagues" (Bansal, 2003, p. 524), or targets. We 
suggest that when sellers choose how to motivate targets, accounting for the target's level of adherence to the social welfare logic is important, as low levels of adherence may or may not coincide with high levels of power. Furthermore, targets may have mixed reasons to support issues, involving both normative and economic aspects.

Second, while considering the ability of change agents is important to explain selling success, equally important is considering how targets respond to issues (Howard-Grenville, 2007; Sonenshein, 2006), as targets' individual responses may promote or preclude organizational-level responses. We argue that one important response to issue selling is the legitimacy judgment of the target (Bitektine and Haack, 2015; Tost, 2011). Legitimacy judgments represent "individual's judgments of the extent to which an entity is appropriate for its social context" (Tost, 2011, p. 689), and are key antecedents of support to change efforts (Suchman, 1995; Tost, 2011). Hence, giving consideration to the legitimacy judgments of selling targets is important if we are to depict a more symmetrical model of meaning construction, in which selling and buying are joint activities (Goffman, 1981; Tannen, 1985). Similar to sellers, targets also have private reasons (Sonenshein, 2006), and are active agents (Cornelissen and Werner, 2014) in the selling process.

In summary, because the success of issue selling hinges on both individual and organizational responses, we argue that social issue sellers must reconcile knowledge of commercial and social welfare logics enacted in organizations and by targets. To unpack how individuals can work with context and target signals, and connect with meaning systems at both levels, we draw on the framing perspective in social movements (Snow et al., 2014) to enrich explanations of social issue selling. 


\section{Social movements, framing, and social issue selling}

We suggest that issue selling, as a process of bottom-up intra-organizational mobilization that seeks to effect change in organizations, can be examined through the lens of social movements (Creed et al., 2002a; Kellogg, 2012; Scully and Segal, 2002; Zald and Berger, 1978).

As Davis and Zald (2005, p. 349) suggest, "the basic dynamics of collective action are common across movements and organizations", in particular at the level of mechanisms. Here, we draw on the theory of framing processes in social movements to expand our understanding of framing mechanisms in issue selling.

Issue framing is a core component of the issue selling process (Dutton and Ashford, 1993). As conceived in this literature, framing is a discursive tactic that, subject to the ability of sellers, increases attention and support to issues. In contrast, in the broader framing literature, and in line with the social movements' perspective, framing processes are conceived as "the active social construction and negotiation of frame-based meanings" (Cornelissen and Werner, 2014, p. 196). In addition, framing processes include not only discursive, but also ideational elements (Snow et al., 2014). This view of framing illuminates the selling processes in two important ways. First, it enables understanding of framing beyond its 'packaging' or discursive dimension by giving consideration to the framing of solutions. Second, it accounts not only for the selling, but also for the buying of ideas (Barnett, 2008), characterizing selling as a conversation that happens as sellers and targets interact and create, negotiate, or contest meanings (Cornelissen and Werner, 2014; Kaplan, 2008).

Specifically, social movement literature examines how activists collectively construct action frames by means of core framing tasks and frame alignment processes (Benford and Snow, 2000; Snow and Benford, 1988; Snow et al., 1986). By engaging the tasks of identifying 
problems (diagnostic framing), developing solutions (prognostic framing), and seeking to motivate others to take part (motivational framing), activists construct and negotiate meaning with their targets in attempts to mobilize action. These framing tasks are accompanied by one or more frame alignment processes, which, as Snow et al. (1986) define, may include bridging (enlisting support outside the focal organization), amplification (invigorating existing values and beliefs), extension (including other issues and concerns of relevance to targets), and transformation (nurturing new meanings and discarding old ones).

We suggest that, in for-profit organizations, the social issue selling process can be better understood by unpacking framing into prognostic and motivational tasks that align meanings among sellers, targets, and organizations. While we acknowledge that diagnostic, prognostic, and motivational framing tasks are interrelated, we work with the assumption that social issue sellers leverage diagnostic frames available in society (Battilana et al., 2009). Hence, we focus on prognostic and motivational framing as the tasks that present and promote visions for change inside organizations (Battilana et al., 2009). In our alternative view of the social issue selling process, we propose that the solutions and motivations that issue sellers attach to social issues will be legitimated subject to how the commercial and the social welfare logics are enacted in organizations, as well as by the targets of selling initiatives (see Figure 1).

\section{INSERT FIGURE 1 ABOUT HERE}

The interplay of core framing tasks and logics in social issue selling

Central to our account of issue selling is the idea that, when an individual attempts to sell an issue to top managers or colleagues in a given organization, s/he attempts to influence the 
legitimacy judgments of these targets. Whereas legitimacy is a collective phenomenon,

legitimacy judgments occur at the individual level, and may differ from collective evaluations

(Tost, 2011). Bitektine and Haack (2015) suggest that legitimacy judgments at the individual

level are formed via two perceptual inputs: validity beliefs, which inform whether the focal entity

conforms to broader cultural expectations (Tost, 2011), by drawing on perceptions of macro-

level validity; and propriety judgments, which inform whether that entity is congruent with the

set of norms selected by evaluators.

Building on these notions, we suggest that the prognostic framing of a social issue may promote positive validity beliefs about it, subject to the compatibility between the commercial and social welfare logics in the organization. This is because the solutions that result from prognostic framing may increase the resonance of the issue by conveying empirical credibility (Benford and Snow, 2000), and thus the feasibility of the issue within the organizational agenda. Implied by this perspective is the idea that selling targets will infer the validity of proposed solutions by assessing their consistency with familiar practices (Cornelissen et al., 2011; De Clercq et al., 2011).

Thus, if a given solution to a social issue is characterized by revenue generation or cost reduction, it will likely engender positive validity beliefs in organizations where the compatibility between the commercial and social welfare logics is high. In this scenario, the solution follows the instrumental template typically associated with corporate sustainability initiatives (Carroll and Shabana, 2010; Gao and Bansal, 2013), in which social value creation is justified to the extent that it also contributes to value capture (Santos, 2012), or the organization's bottom line. We refer to these solutions as win-win solutions (Elkington, 1994). 
Hence, positive change may emerge as an outcome of profit seeking, or as a byproduct of products and services (Gao and Bansal, 2013; Haigh and Hoffman, 2014).

Under these circumstances, successful solutions will likely include prescriptions of the social welfare logic that not only fail to conflict with the prescriptions of the core commercial logic, but also enhance them. If a given solution presents weak potential for revenue generation or cost reduction, then it is less likely to be legitimated in this scenario. For example, in the microprocessor manufacturing company studied by Howard-Grenville (2007), the environmental specialists leading the Blue Skies project successfully sold an air emissions solution to the technical team because it represented an opportunity to eliminate a constraint on manufacturing capacity. The Recycler project solution, however, was not advanced. Issue sellers wanted to promote the adoption of recycling equipment to reuse chemical waste, but they could not justify the initiative in terms of return on investment. Because the company only adopted the prescriptions of the social welfare logic that would enhance their commercial goals, sellers had little success when proposing solutions without clear financial benefits. In another example, Hugh Saddington at Telstra introduced a marketing strategy focused on reducing clients' carbon footprint through the company's information technology (Grayson et al., 2014). By creating sustainability calculators and establishing a strong business case, he made his idea resonate with the organization's logic.

On the other hand, if a given solution to a social issue reflects prioritization of societal and environmental concerns over economic benefits, it will likely engender positive validity beliefs in organizations where the compatibility between the commercial and the social welfare logic can be low. In this scenario, the solution may advance a systemic approach to corporate sustainability, embracing the contradictions that may arise among the financial, social, and 
environmental dimensions of companies' activities. We refer to these solutions as integrative solutions (Gao and Bansal, 2013). Because the context allows for low compatibility between the commercial and social welfare logics, value creation prevails over value capture (Santos, 2012), and positive change may emerge as a purposeful effort, rather than as a byproduct of companies' activities (Haigh and Hoffman, 2014).

Under these circumstances, successful solutions will likely include prescriptions of the social welfare logic that may be independent from-or contradictory to-the prescriptions of the core commercial logic. If a given solution presents weak potential for directly addressing important societal and environmental concerns, then it is less likely to be legitimated in this scenario. The case of Gib Bulloch at Accenture exemplifies this approach to prognostic framing. After a year of voluntarily offering his business skills to develop a support center for enterprises in an impoverished area of Macedonia, Bulloch had the idea of replicating and scaling his experience through Accenture (Grayson et al., 2014). Having identified the opportunity to offer high-quality consulting services to build the capacity of organizations in the international development sector, Bulloch devised the creation of a corporate social enterprise. The business model epitomized the enactment of prescriptions in contradiction to the goals of the commercial logic: Accenture would cut margins to zero and absorb overheads, and consultants would take a salary cut during their assignments. Though not aimed at generating profits, the model had to be financially viable; hence clients would pay significantly reduced rates for consulting services. Although Bulloch's idea was groundbreaking in itself, enacting prescriptions of the social welfare logic without expectations for bottom line improvements was not entirely new at Accenture. In an environment characterized by employees taking sabbaticals for voluntary service assignments, pro bono 
activities, and a corporate foundation (Bulloch, 2012), Bulloch could find fertile ground for his 'not-for-loss' solution.

In another example, Arup engineer Jo da Silva conceived a spin-off consultancy business to address urbanization challenges and disaster risk reduction in developing countries (Grayson et al., 2014). Although her venture was proposed as a self-sustainable business, it would operate on lower margins than Arup's commercial accounts, and on a not-for-profit model. This solution aligned with the logic composition of the company, which from inception emphasized humanitarianism.

Hence, we suggest that solutions to social issues that resonate with how the commercial and the social welfare logics are enacted in the fabric of organizations will likely conform to broader cultural expectations observed by selling targets (see Figure 1 for links with proposition keys):

Proposition 2a: Solutions to social issues that subordinate the social welfare logic to the commercial logic (1) will likely promote validity beliefs when compatibility between these logics is high (A).

Proposition 2b: Solutions to social issues that subordinate the commercial logic to the social welfare logic (2) will likely promote validity beliefs when compatibility between these logics is low $(B)$.

When framing issues, however, sellers engage not only in meaning creation, but also in activation of the cognitive frames or schemas of selling targets (Cornelissen and Werner, 2014; Howard-Grenville, 2007). Hence, solutions can only advance responses to social issues if key organizational constituents are motivated to offer support or take action. Social movement research suggests that motivational framing tasks build on vocabularies of motive (Benford and 
Snow, 2000), which may assume one of two different linguistic codes: a restricted code or an elaborated code (Bernstein, 1971; Snow and Benford, 1992).

Motivational framing based on restricted vocabularies of motive implies the use of words that reflect the organization's immediate social structure and provide a narrow range of ideas, thus being predictable and allowing little room for varied interpretations (Snow and Benford, 1992). In contrast, motivational framing based on elaborated vocabularies of motive implies the application of a wider range of ideas, thus being more flexible and "less predictable and reflective of immediate structures" (Snow and Benford, 1992, p. 139).

We suggest that the motivational framing of a social issue may promote positive propriety judgments about it, subject to how sellers apply vocabularies of motive that connect with their targets. This connection, we argue, depends on the level of selling targets' adherence to the social welfare logic (Besharov and Smith, 2014), which represents how they may differ on the sets of norms they select to evaluate issues (Bitektine and Haack, 2015).

Targets of issue selling initiatives may vary in values, beliefs, job positions, and functions, which inform their enacting of commercial and social welfare logics in daily activities. Whereas it can be expected that in a for-profit organization most members will adhere to the overarching commercial logic in order to fulfill the requirements of their job descriptions, adhering to the social welfare logic may, in contrast, result from individual preferences or job expectations associated with specific positions.

Hence, if the motivational framing task is characterized by restricted vocabularies of motive, it will likely engender positive propriety judgments when selling targets demonstrate low adherence to the social welfare logic. In the context of for-profit organizations, restricted vocabularies of motive build on an instrumental basis of legitimacy, raising notions of 
"effectiveness, efficiency, or utility" (Tost, 2011, p. 693). By focusing on instrumental motives, restricted vocabularies may advance the business case for social issues, linking tentative solutions to the commercial interests of organizations.

One of the environmental specialists in Howard-Grenville's (2007) study offers an example of this type of motivational framing. After perceiving the low adherence of his targets to the social welfare logic, the seller decided to redefine an environmental issue as operational. He then presented a slide to the technical team showing how the emissions of hazardous air pollutants would have a negative impact on the company's manufacturing goals (Howard-Grenville and Hoffman, 2003). Rather than amplifying the values associated with the need of reducing emissions, the seller extended the frame (Snow et al., 1986) of the issue to the operational realm, emphasizing instrumental motives that would connect with the values and beliefs of selling targets. Similarly, Telstra's Hugh Saddington had to redefine his motivational frame on business case terms, as the firm's directors were initially skeptical about his idea of addressing climate change through information technology (Grayson et al., 2014).

On the other hand, if the motivational framing task is characterized by elaborated vocabularies of motive, it will likely engender positive propriety judgments when selling targets demonstrate high adherence to the social welfare logic. Elaborated vocabularies of motive may include instrumental aspects, but also build on both relational and moral bases of legitimacy, raising notions of "fairness, benevolence, or communality" and "morality, ethicality, or integrity" (Tost, 2011, p. 694). By focusing on relational motives, elaborated vocabularies may advance social issues, establishing the role of organizations in fulfilling the interests of different stakeholder groups. In turn, by focusing on moral motives, vocabularies can emphasize higherorder values or stewardship interests (Aguilera et al., 2007). 
The example of Accenture's Gib Bulloch again illustrates our proposition. After devising a business model for a corporate social enterprise within Accenture, Bulloch's first step was to approach the chairman. He went on to write a faux press article set six months in the future, in which the chairman was commended in the World Economic Forum for launching an innovative not-for-profit business unit (Grayson et al., 2014). In the article, Bulloch portrayed the chairman as transcending the dichotomy between business and society, and highlighted the multiple advantages of the enterprise for Accenture, stakeholders, and broader society, with particular focus on the mutually beneficial relationships it would promote (Rogan and Bode, 2014). In his fictitious piece, Bulloch even conferred a knighthood to the chairman (TEDx Talks, 2013), a symbol of significant contribution to national life in the United Kingdom. By adopting an inclusive language and elevating stewardship and stakeholder interests in his text, Bulloch amplified the values (Snow et al., 1986) of the social issue he wished to promote, as he perceived the chairman as supportive of the social welfare logic.

Jo da Silva's selling of her Arup International Development venture also exemplifies this approach to motivational framing. In persuading top management at Arup, she framed her project as a business that would complement the company's charitable activities and help fulfill its mission 'to shape a better world' (Grayson et al., 2014).

Hence, we suggest that motivations related to social issues may align meanings between sellers and targets by drawing on specific vocabularies of motive that connect with the sets of norms targets use to evaluate issues (see Figure 1 for links with proposition keys):

Proposition 3a: Motivations to address social issues built on restricted vocabularies (3) will likely promote positive propriety judgments when the target's adherence to the social welfare logic is low (a). 
Proposition 3b: Motivations to address social issues built on elaborated vocabularies (4)

will likely promote positive propriety judgments when the target's adherence to the social

welfare logic is high (b).

\section{Social issue selling approaches}

Although elaborated vocabularies would be the most authentic means to motivate integrative solutions, and restricted vocabularies to motivate win-win solutions, sellers proposing both types of solutions will usually have to engage targets who hold different levels of adherence to the social welfare logic. Particularly in these cases, the issue seller may prevent negative reactions by adopting a 'logic of appropriateness' (Campbell, 2005), and attempting to influence the recognition of social issues as both strategically relevant and viable. We thus suggest that, subject to how logics are enacted in organizations and by targets, solutions and motivations can be combined to represent four distinct social issue selling approaches: the cost-benefit sell, the enlightened self-interest sell, the Trojan horse sell, and the paradoxical sell (see Figure 2). We next describe these selling approaches, referring to the key used in our propositions and Figure 1 to note links to the process model advanced above.

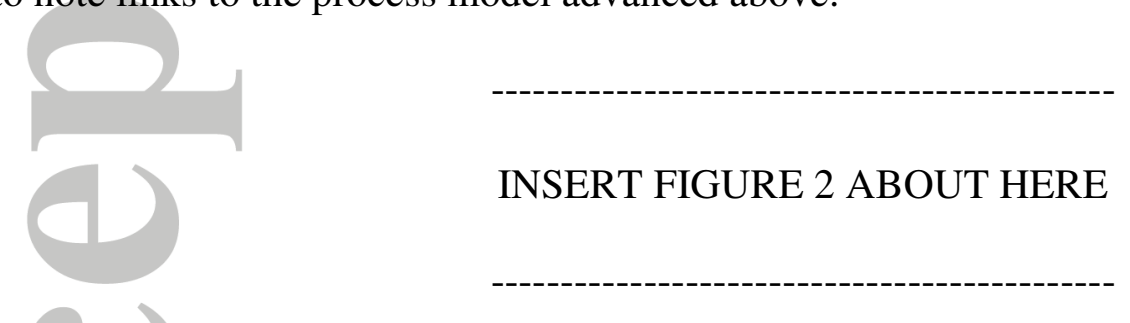

The cost-benefit sell may occur when the seller interprets compatibility between the commercial and social welfare logics as potentially high (A), and the target's level of adherence to the social welfare logic as low (a). In this case, the seller would design a win-win solution (1) to a given social issue, and attempt to motivate the selling target with a restricted vocabulary (3).

We call this selling approach cost-benefit because both the solution and the motivation attached 
to it subordinate the social issue to financial concerns (Oliver, 1991). Through this approach, the seller evokes the commercial interests of the organization and the selling target. Although the proposed solution may contribute to social value creation, it is advanced on the basis of win-win arguments (Kreps and Monin, 2013), and thus can be best promoted through restricted vocabularies that emphasize instrumental motives. The earlier examples of Hugh Saddington at Telstra (Grayson et al., 2014) and of the environmental specialist linking emissions to manufacturing goals at Chipco (Howard-Grenville, 2007) illustrate this selling approach. The enlightened self-interest sell may also occur when the seller interprets compatibility between the commercial and social welfare logics as potentially high (A). However, in this case, the selling target is perceived to have a high level of adherence to the social welfare logic (b), leading the seller to motivate a win-win solution (1) through an elaborated vocabulary (4). We call this approach enlightened self-interest because the motivation attached to the proposed solution attempts to balance the idea's commercial and social value (Oliver, 1991). Targets of this selling approach are perceived to have a more differentiated belief structure, and to welcome the possibility of 'doing well while doing good.' Although the designed solution clearly aligns social concerns with commercial goals, the motivation to justify it goes beyond economic reasons, highlighting relational and moral motives. This approach can be observed in Bansal's (2003) example of the manufacturing company Alpha, where employees successfully sold an office-waste management issue by referring to 'corporate citizenship', 'added value', and 'quality'. In the example of Danish biotech Novozymes, top managers were also perceived as supportive of the social welfare logic (Olsen and Boxenbaum, 2009). To promote the idea of an enzyme technology that could increase the nutritional value of basic food products, one of the 
sellers at Novozymes linked the solution to the United Nations Millennium Development Goals, and simultaneously to the commercial potential of bottom of the pyramid markets.

The Trojan horse sell may occur when the seller interprets compatibility between the commercial and social welfare logics as potentially low (B), and the target's level of adherence to the social welfare logic as low (a). In this case, the seller may design an integrative solution (2) to a given social issue, and attempt to motivate the selling target with a restricted vocabulary (3). We label this approach the Trojan horse because the motivation attached to the solution for the social issue conceals its integrative nature. Targets of this selling approach are perceived to have a less differentiated belief structure and a high level of embeddedness in financial institutions, usually associated with profit maximization, diminished cooperation, and low altruism (Almandoz, 2012). Through this approach, the seller pursues the approval of the target by subordinating the social issue to financial concerns. Creed et al.'s (2002a) account of how groups of employees promoted policies for eliminating workplace discrimination against LGBT may exemplify this approach. Specifically, though some organizations demonstrated strong corporate citizenship, employees had to develop a business case for nondiscrimination to sway decision-makers concerned with costs. The selling of an IBM 'Corporate Peace Corps' by Kevin Thompson also has characteristics of a Trojan horse approach. Even when changes in the organizational logic opened space for his idea, it had to be justified on the basis of contributing to cost effectiveness in internationalization and the potential to gain experience in new markets (Davis and White, 2015).

Lastly, the paradoxical sell may also occur when the seller interprets compatibility between commercial and social welfare logics as potentially low (B). However, in this case, the selling target is perceived to have a high level of adherence to the social welfare logic (b), leading the 
seller to motivate an integrative solution (2) through an elaborated vocabulary (4). We call this selling approach paradoxical because both the solution and the motivation attached to it demonstrate that elements often seen as contradictory can co-exist (Lewis, 2000; Smith and Lewis, 2011); that is, that the tensions that may arise between social value creation and the bottom line can be successfully managed. Through this approach, the seller identifies 'both/and' solutions and motivations, leveraging the "synergies and distinctions of the opposing elements" (Lewis et al., 2014, p. 61), and juxtaposing economic and social concerns (Hahn et al., 2014). This approach can also be considered the most authentic for sellers of integrative solutions. Because integrative solutions are complex and combine multiple frame elements (Gao and Bansal, 2013; Hahn et al., 2014), such solutions are best motivated through elaborated vocabularies. If the seller perceives the target to have a more differentiated belief structure (Dutton and Ashford, 1993) and to be supportive of the social welfare logic, integrative solutions can be linked to relational and moral motives. In this case, the social issue does not imply subordination to a financial concern (Kreps and Monin, 2013). This selling approach is typified in the previous examples of Gib Bulloch at Accenture, and Jo da Silva at Arup (Grayson et al., 2014).

The four selling approaches described above illustrate the different ways in which successful social issue selling can unfold in for-profit organizations. In practice, sellers may mix and match tentative solutions and motivations with different contexts and targets to achieve varying degrees of success. Yet these ideal selling approaches suggest what type of solutions (win-win or integrative) and vocabularies of motive (restricted or elaborated) are likely to connect with the meaning systems of organizations and targets, and generate positive legitimacy judgments that enable social issue selling success. A paradoxical selling approach would have little effect with 
companies and targets like those described in Howard-Grenville's (2007) study. Likewise, a cost-benefit sell would fail to tap into the passion of supporters and the organizational ethos of companies like Arup (Grayson et al., 2014).

In summary, logics and vocabularies are the materials social issue sellers employ to craft framing tasks and interact with selling targets. We suggest that the degree to which the prognostic and motivational framing of a social issue engenders conditional support is mediated by the legitimacy judgments of selling targets, such that support is stronger when framing tasks connect with both validity beliefs and propriety judgments (Bitektine and Haack, 2015).

Importantly, we do not assume that the support of key selling targets automatically translates into the acceptance of proposed solutions and their implementation. The idea that support is conditional reminds us that framing is a negotiation of meaning (Cornelissen and Werner, 2014), and that other factors beyond the scope of the seller-target interaction may also determine a selling initiative's success. These initial encounters between sellers and targets, however, may play an important role in shaping social innovation in for-profit organizations, as our model illustrates.

\section{DISCUSSION AND CONCLUSION}

In this paper, we explain the process by which the tactics of social issue sellers in forprofit organizations may align with meanings held by organizations and targets of selling initiatives. We advance understanding of issue selling by proposing how sellers may draw on knowledge of logics (Besharov and Smith, 2014) and vocabularies of motive (Snow and Benford, 1992) to craft prognostic and motivational framing tasks (Benford and Snow, 2000) that promote targets' legitimacy judgments (Bitektine and Haack, 2015; Tost, 2011). While issue selling has been a topic of interest for researchers of social issues in management (Bansal, 2003; 
Howard-Grenville, 2007; Sonenshein, 2006, 2014), prior research has conflated the craft of solutions (prognostic framing) with that of motivations (motivational framing), and overlooked the ways in which sellers can reconcile context and target signals to advance social issues. We complement and extend this research by forwarding a set of propositions and four selling approaches that illustrate how sellers can successfully craft tentative solutions and motivations to social issues, shedding light on the intricate relationships of meaning-making by sellers, organizations, and selling targets when contrasting logics are involved.

Since our focus is on the framing processes in issue selling, this raises the question of whether selling and framing are interchangeable terms in our account. We see framing as a key component of the broader selling process, and we argue that two characteristics of the selling process distinguish it from other accounts of strategic framing. First, issue selling is a "critical activity in the early stages of organizational decision-making processes" (Dutton and Ashford, 1993, p. 397). Second, it is mainly a bottom-up process. In contrast, research on framing in organizational settings has traditionally focused, with exceptions (e.g., Creed et al., 2002a), on framing initiated by top managers or institutional actors (e.g., regulators) at multiple stages of organizational decision-making processes (e.g., Etzion and Ferraro, 2010; Fiss and Zajac, 2006; Kellogg, 2009; Sonenshein, 2010). This differentiation is important because in issue selling the seller, or group of sellers, "does not have the authority to make impactful decisions, but can initiate proactive actions to create strategic input that will persuade top management to consider and authorize preferable actions" (Pandza, 2011, p. 1018).

Hence, we suggest that a focus on framing as a mechanism of issue selling can enrich both literatures. The framing lenses recast selling as a conversation, and as a process rooted in social interaction, in which the seller's ability cannot be separated from the target's response. 
Furthermore, by looking at framing from the perspective of prognostic and motivational tasks, we gain insight into both the discursive and ideational aspects of selling initiatives. At the same time, the attributes that are specific to issue selling processes—namely, sellers' lack of authority and their intent to initiate strategic change-may shed light on the 'small encounters' (Snow et

$a l .$, 1986) between social movement entrepreneurs and targets, enhancing explanations of how frame resonance is achieved through interaction (Cornelissen et al., 2015; Snow et al., 2014).

While framing processes provide us with a language (Zald, 2008) to talk about how social movements may emerge in organizations through the work of issue sellers, our attention to logics builds on trends in rhetorical institutionalism literature (Green and Li, 2011) to shed light on the politics of issue selling. By linking institutional logics to the work of social issue sellers, we offer a more nuanced understanding of context and target signals for selling, suggesting how sellers can tap into broader discourses and targets' interests to craft credible, attractive stories for different audiences (Lefsrud and Jennings, 2014; Martens et al., 2007).

We consider, also, that the social welfare logic may develop along a continuum that progresses from avoiding harmful activities to social betterment, and that the commercial logic may develop along a continuum that spans from financial viability to profit maximization.

Following this premise, different levels of compatibility between social welfare and commercial logics are possible at the organizational level (Besharov and Smith, 2014), as are different levels of targets' adherence to the social welfare logic. Our arguments suggest that sellers who accurately observe logic compatibility and adherence at both levels will be better equipped to craft solutions and motivations that engage selling targets.

In particular, our illustration of selling approaches demonstrates that social issue sellers can galvanize the social responsibility of companies beyond the traditional business case. 
Although previous research suggests that issue sellers operating in for-profit organizations will usually resort to instrumental framing approaches (Dutton et al., 2001; Sonenshein, 2006), we demonstrate that subject to how organizations enact their commercial and social welfare logics, issue sellers may find the space to advance integrative solutions (Gao and Bansal, 2013) to social issues. Our propositions hence contribute to a positively deviant view of issue selling (Haigh and Hoffman, 2014), in which sellers may go beyond mainstream practices to create pockets of hybridization in organizations (Battilana and Lee, 2014). This is particularly important because if the social welfare logic can only be enacted in ways that contribute to commercial objectives, this "will mask important potential for positive corporate contributions to sustainable development" (Hahn et al., 2010, p. 218). Hence, high compatibility between commercial and social welfare logics in for-profit contexts may not always be desirable. Furthermore, we also show that subject to the adherence of targets to the social welfare logic, issue sellers may comfortably use vocabularies that reveal relational and moral motives (Aguilera et al., 2007; Tost, 2011). This observation highlights that issue selling efforts need not lack moral meaning (Bansal, 2003; Crane, 2000), and that social issue sellers may find the scope to pursue initiatives that are both authentic and consistent with their private reasons and beliefs (De Clercq et al., 2011; Meyerson and Scully, 1995; Sonenshein, 2006).

Collectively, our contributions to issue selling theory also add to the microfoundations of CSR, or the "foundations of CSR that are based on individual action and interaction" (Aguinis and Glavas, 2012, p. 956). By focusing on the role of the internal social change agent, we expand recent bottom-up perspectives to the promotion of CSR initiatives (e.g., Sharma and Good, 2013; Sonenshein, 2014), and complement theoretical contributions focused on the cognitive frames of 
top managers in relation to corporate sustainability and stakeholder concerns (e.g., Bundy et al.,

2013; Hahn et al., 2014).

\section{Practical implications}

Our focus on the actions of individuals selling social issues in for-profit organizations uncovers important implications for practice. Previous research suggests that the more sellers accumulate knowledge about organizations, the more successful they are in attracting top management attention (Dutton et al., 2001; Howard-Grenville, 2007; Rouleau and Balogun, 2011). Our propositions provide insight into the content of this knowledge, which may draw on interpretations of compatibility between commercial and social welfare logics at the organizational level, and on interpretations of targets' level of adherence to the social welfare logic. Hence, our work may help internal social change agents engage selling efforts that rely more on a practical intelligence (Dutton et al., 2001) of organizations and targets rather than on stylistic preferences (Piderit and Ashford, 1993).

Because profitability is not the sole criterion of success in social issue selling, such initiatives may improve cognitive plurality as related to corporate sustainability (Hahn and Aragón-Correa, 2015). Issue sellers may increase the level of integration of commercial and social welfare logics over time (Battilana and Lee, 2014), further contributing to shifts in organizational logics (Kaplan, 2008). Hence, social issue selling initiatives may help organizations respond to institutional complexity (Greenwood et al., 2011), and reduce the cognitive dissonance that arises from stakeholder demands that depart from the dominant logic (Bundy et al., 2013). Organizations wishing to benefit from social issue selling action need to provide opportunity structures that help individuals overcome the cognitive challenges that are 
frequently associated with complex social issues (Sonenshein et al., 2014), in order to improve

the capability and psychological safety of potential sellers (Dutton et al., 1997).

\section{Future research}

Our social issue selling account is not without limitations. While we aim to expand our understanding of the contextually situated nature of issue selling (Dutton et al., 2001), it is not our intention to be exhaustive. Previous research suggests that characteristics of sellers such as credibility, values, and individual discretion, as well as their decisions about how to perform selling - such as timing, networking, and coalition building (Andersson and Bateman, 2000; Bansal, 2003; Dutton et al., 2001; Howard-Grenville, 2007; Meyerson and Scully, 1995)—are important conditions shaping issue selling processes of any nature. Furthermore, selling processes may also be influenced by institutional factors such as competitive and economic pressures, levels of uncertainty, and national culture, along with further organizational factorssuch as resource slack, the predictability of policy windows, family structure, and target power (Bansal, 2003; Dutton et al., 1997; Ling et al., 2005, 2012; Ren and Guo, 2011; Scully and Segal, 2002; Sonenshein, 2006). To increase focus and parsimony, we excluded these conditions from our theory development.

However, we hope to have provided a foundation upon which empirical studies can be developed to extend our reasoning and expand research on specific social issues. Testing our propositions will require, ideally, tracking the progress of issue sellers in their prognostic and motivational framing tasks through time, due to the recursive nature of framing processes (Bansal, 2003; Dutton and Ashford, 1993; Howard-Grenville, 2007; Sonenshein, 2014). Mixed method studies may be particularly suited to study our model. For example, information from social issue sellers and targets could be gathered via a combination of diary studies, interviews, 
and field visits at different stages of the selling process, allowing for both frame analysis (e.g., Creed et al., 2002b) and the observation of micro-level discursive strategies (e.g., Kwon et al., 2014; Rouleau, 2005). The composition of the organizational logic could be analyzed through cognitive mapping techniques similar to those used by Crilly and Sloan (2012), or through the vocabulary perspective advanced by Loewenstein et al. (2012). Strategy-as-practice approaches could also provide insights connecting the discourse of issue sellers to gestures and sociomaterial practices (Balogun et al., 2014; Cornelissen et al., 2015; Fairclough, 2003). Furthermore, the adherence of targets to the social welfare logic could be measured through targets' observable network ties (Greenwood et al., 2011).

Importantly, future research should pay attention to the co-construction of meaning in issue selling, treating framing tasks as interactive processes, and considering both sellers and targets as communication agents (Cornelissen et al., 2015). In order to shape and influence interpretations, the framing tasks of issue sellers need to align with the actual motives of selling targets (Cornelissen et al., 2011; Cornelissen and Werner, 2014; Rouleau and Balogun, 2011), and group dynamics may also play an important role (e.g., Pandza, 2011). Future studies on the outcomes of issue selling processes could consider these ideas to shed light on how issue sellers not only work with sponsors, but also through gatekeepers (Markham et al., 2010) or antagonists (Lefsrud and Meyer, 2012) to establish frame resonance and further mobilize resources for change.

Finally, we are hopeful that our propositions will contribute to extending research on corporate social entrepreneurship (Austin and Reficco, 2009; Bode and Santos, 2013; Hemingway, 2005), or social intrapreneurship (Brenneke and Spitzeck, 2010; Halme et al., 2012; Kistruck and Beamish, 2010). We suggest that our social issue selling model may be particularly 
useful in explaining how individuals may apply the principles of social entrepreneurship inside corporations (Dacin et al., 2011; Mair and Martí, 2006), contributing to initiatives that may range from bottom of the pyramid innovations (Prahalad and Hart, 2002), to paradoxical solutions (Hahn et al., 2014) to corporate sustainability and societal issues.

\section{REFERENCES}

Aguilera, R. V., Rupp, D. E., Williams, C. A. and Ganapathi, J. (2007). 'Putting the S back in corporate social responsibility: A multilevel theory of social change in organizations'. Academy of Management Review, 32, 836-63.

Aguinis, H. and Glavas, A. (2012). 'What we know and don't know about corporate social responsibility: A review and research agenda'. Journal of Management, 38, 932-68.

Almandoz, J. (2012). 'Arriving at the starting line: The impact of community and financial logics on new banking ventures'. Academy of Management Journal, 55, 1381-406.

Almandoz, J. (2014). 'Founding teams as carriers of competing logics: When institutional forces predict banks' risk exposure'. Administrative Science Quarterly, 59, 442-73.

Andersson, L. M. and Bateman, T. S. (2000). 'Individual environmental initiative: Championing natural environmental issues in U.S. business organizations'. Academy of Management Journal, 43, 548-70.

Ansoff, H. I. (1980). 'Strategic issue management'. Strategic Management Journal, 1, 131-48. Ashford, S. J., Rothbard, N. P., Piderit, S. K. and Dutton, J. E. (1998). 'Out on a limb: The role of context and impression management in selling gender-equity issues'. Administrative Science Quarterly, 43, 23-57.

Austin, J. and Reficco, E. (2009). Corporate Social Entrepreneurship. Working Paper 09-101, Harvard Business School, Boston, MA. 
Balogun, J., Jacobs, C., Jarzabkowski, P., Mantere, S. and Vaara, E. (2014). 'Placing strategy discourse in context: Sociomateriality, sensemaking, and power'. Journal of Management Studies, 51, 175-201.

Bansal, P. (2003). 'From issues to actions: The importance of individual concerns and organizational values in responding to natural environment issues'. Organization Science, $14,510-27$.

Barnett, M. L. (2008). ‘An attention-based view of real options reasoning'. Academy of Management Review, 33, 606-28.

Battilana, J. and Lee, M. (2014). 'Advancing research on hybrid organizing - Insights from the study of social enterprises'. Academy of Management Annals, 8, 397-441.

Battilana, J., Leca, B. and Boxenbaum, E. (2009). 'How actors change institutions: Towards a theory of institutional entrepreneurship'. Academy of Management Annals, 3, 65-107.

Benford, R. D. and Snow, D. A. (2000). 'Framing processes and social movements: An overview and assessment'. Annual Review of Sociology, 26, 611-39.

Bernstein, B. (1971). Class, Codes and Control. Volume 1: Theoretical Studies Towards a Sociology of Language. London: Routledge and Kegan Paul.

Besharov, M. L. and Smith, W. K. (2014). 'Multiple institutional logics in organizations: Explaining their varied nature and implications'. Academy of Management Review, 39, 36481.

Bies, R. J., Bartunek, J. M., Fort, T. L. and Zald, M. N. (2007). 'Corporations as social change agents: Individual, interpersonal, institutional, and environmental dynamics'. Academy of Management Review, 32, 788-93. 
Bitektine, A. and Haack, P. (2015). 'The macro and the micro of legitimacy: Towards a multilevel theory of the legitimacy process'. Academy of Management Review, 40, 49-75.

Bode, C. S. and Santos, F. (2013). The Organizational Foundations of Corporate Social Entrepreneurship. Working paper 2013/07/EFE/ST/ICE, INSEAD, Fontainebleau, France.

Brenneke, M. and Spitzeck, H. (2010). 'Social intrapreneurs - Bottom-up social innovation'. International Review of Entrepreneurship, 8, 157-76.

Bulloch, G. (2012). Inside-Out Transformation: A Hybrid Business Model for a Converging World. Available at: http://www.managementexchange.com/story/isnide-out-transformation (accessed 13 November 2014).

Bundy, J., Shropshire, C. and Buchholtz, A. K. (2013). 'Strategic cognition and issue salience: Toward an explanation of firm responsiveness to stakeholder concerns'. Academy of Management Review, 38, 352-76.

Burgelman, R. A. (1983). 'A process model of internal corporate venturing in the diversified major firm'. Administrative Science Quarterly, 28, 223-44.

Campbell, J. L. (2005). 'Where do we stand? Common mechanisms in organizations and social movements research'. In Davis, G. F., McAdam, D., Scott, W. R. and Zald, M. N. (Eds), Social Movements and Organization Theory. New York: Cambridge University Press, 41-72. Carroll, A. B. and Shabana, K. M. (2010). 'The business case for corporate social responsibility: A review of concepts, research and practice'. International Journal of Management Reviews, 12, 85-105.

Cornelissen, J. P., Durand, R., Fiss, P. C., Lammers, J. C. and Vaara, E. (2015). 'Putting communication front and center in institutional theory and analysis'. Academy of Management Review, 40, 10-27. 
Cornelissen, J. P., Holt, R. and Zundel, M. (2011). 'The role of analogy and metaphor in the framing and legitimization of strategic change'. Organization Studies, 32, 1701-16.

Cornelissen, J. P. and Werner, M. D. (2014). 'Putting framing in perspective: A review of framing and frame analysis across the management and organizational literature'. Academy of Management Annals, 8, 181-235.

Crane, A. (2000). 'Corporate greening as amoralization'. Organization Studies, 21, 673-96.

Creed, W. D., Langstraat, J. A. and Scully, M. A. (2002b). 'A picture of the frame: Frame analysis as technique and as politics'. Organizational Research Methods, 5, 34-55.

Creed, W. D., Scully, M. A. and Austin, J. R. (2002a). 'Clothes make the person? The tailoring of legitimating accounts and the social construction of identity'. Organization Science, 13, 475-96.

Crilly, D. and Sloan, P. (2012). 'Enterprise logic: Explaining corporate attention to stakeholders from the 'inside-out'. Strategic Management Journal, 33, 1174-93.

Dacin, M. T., Dacin, P. A. and Tracey, P. (2011). 'Social entrepreneurship: A critique and future directions'. Organization Science, 22, 1203-13.

Davis, G. and White, C. (2015). Changing Your Company from the Inside Out: A Guide for Social Intrapreneurs. Boston, MA: Harvard Business Review Press.

Davis, G. F. and Zald, M. N. (2005). 'Social change, social theory, and the convergence of movements and organizations'. In Davis, G. F., McAdam, D., Scott, W. R. and Zald, M. N. (Eds), Social Movements and Organization Theory. New York: Cambridge University Press, $335-50$.

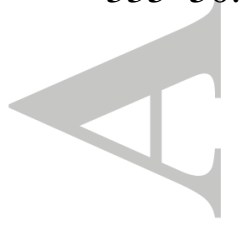


De Clercq, D., Castañer, X. and Belausteguigoitia, I. (2011). 'Entrepreneurial initiative selling within organizations: Towards a more comprehensive motivational framework'. Journal of Management Studies, 48, 1269-90.

Dutton, J. E. and Ashford, S. J. (1993). 'Selling issues to top management'. Academy of Management Review, 18, 397-428.

Dutton, J. E., Ashford, S. J., Lawrence, K. A. and Miner-Rubino, K. (2002). 'Red light, green light: Making sense of the organizational context for issue selling'. Organization Science, 13, 355-69.

Dutton, J. E., Ashford, S. J., O’Neill, R. M. and Lawrence, K. A. (2001). 'Moves that matter: Issue selling and organizational change'. Academy of Management Journal, 44, 716-36.

Dutton, J. E., Ashford, S. J., O’Neill, R. M., Hayes, E. and Wierba, E. E. (1997). 'Reading the wind: How middle managers assess the context for selling issues to top managers'. Strategic Management Journal, 18, 407-25.

Dutton, J. E. and Duncan, R. B. (1987). 'The creation of momentum for change through the process of strategic issue diagnosis'. Strategic Management Journal, 8, 279-95.

Elkington, J. (1994). 'Towards the sustainable corporation: Win-win-win business strategies for sustainable development'. California Management Review, 36, 90-100.

Etzion, D. and Ferraro, F. (2010). 'The role of analogy in the institutionalization of sustainability reporting'. Organization Science, 21, 1092-107.

Fairclough, N. (2003). Analyzing Discourse - Textual Analysis for Social Research. London: Longman.

Fiss, P. C. and Zajac, E. J. (2006). 'The symbolic management of strategic change: Sensegiving via framing and decoupling'. Academy of Management Journal, 49, 1173-93. 
Freeman, R. (1984). Strategic Management: A Stakeholder Approach. Cambridge, MA:

Cambridge University Press.

Friedland, R. and Alford, R. R. (1991). 'Bringing society back in: Symbols, practices, and institutional contradictions'. In Powell, W. W. and DiMaggio, P. J. (Eds), The New Institutionalism in Organizational Analysis. Chicago, IL: University of Chicago Press, 23263.

Gao, J. and Bansal, P. (2013). 'Instrumental and integrative logics in business sustainability'. Journal of Business Ethics, 112, 241-55.

Gattiker, T. F., Carter, C. R., Huang, X. and Tate, W. L. (2014). 'Managerial commitment to sustainable supply chain management projects'. Journal of Business Logistics, 35, 318-37. Goffman, E. (1981). Forms of Talk. Philadelphia, PA: University of Pennsylvania Press. Grayson, D., McLaren, M. and Spitzeck, H. (2014). Social Intrapreneurism and All That Jazz: How Business Innovators Are Helping to Build a More Sustainable World. Sheffield: Greenleaf Publishing.

Green Jr, S. E. and Li, Y. (2011). 'Rhetorical institutionalism: Language, agency, and structure in institutional theory since Alvesson 1993'. Journal of Management Studies, 48, 1662-97.

Greenwood, R., Raynard, M., Kodeih, F., Micelotta, E. and Lounsbury, M. (2011). 'Institutional complexity and organizational responses'. Academy of Management Annals, 5, 317-71.

Hahn, T. and Aragón-Correa, J. A. (2015). ‘Toward cognitive plurality on corporate sustainability in organizations: The role of organizational factors'. Organization \& Environment, 28, 255-63.

Hahn, T., Figge, F., Pinkse, J. and Preuss, L. (2010). ‘Trade-offs in corporate sustainability: You can't have your cake and eat it'. Business Strategy and the Environment, 19, 217-29. 
Hahn, T., Preuss, L., Pinkse, J. and Figge, F. (2014). 'Cognitive frames in corporate sustainability: Managerial sensemaking with paradoxical and business case frames'. Academy of Management Review, 39, 463-87.

Haigh, N. and Hoffman, A. J. (2014). 'The new heretics: Hybrid organizations and the challenges they present to corporate sustainability'. Organization and Environment, 27, 22341.

Halme, M., Lindeman, S. and Linna, P. (2012). 'Innovation for inclusive business: Intrapreneurial bricolage in multinational corporations'. Journal of Management Studies, 49, $743-84$.

Helms, W., Oliver, C. and Webb, K. (2012). 'Antecedents of settlement on a new institutional practice: Negotiation of the ISO 26000 standard on social responsibility'. Academy of Management Journal, 55, 1120-45.

Hemingway, C. A. (2005). 'Personal values as a catalyst for corporate social entrepreneurship'. Journal of Business Ethics, 60, 233-49.

Howard-Grenville, J. A. (2007). 'Developing issue-selling effectiveness over time: Issue selling as resourcing'. Organization Science, 18, 560-77.

Howard-Grenville, J. A. and Hoffman, A. J. (2003). 'The importance of cultural framing to the success of social initiatives in business'. Academy of Management Executive, 17, 70-84.

Howell, J. M. and Boies, K. (2004). 'Champions of technological innovation: The influence of contextual knowledge, role orientation, idea generation, and idea promotion on champion emergence'. Leadership Quarterly, 15, 123-43.

Howell, J. M. and Higgins, C. A. (1990). 'Champions of technological innovation'. Administrative Science Quarterly, 35, 317-41. 
Jones, C. and Livne-Tarandach, R. (2008). 'Designing a frame: Rhetorical strategies of architects'. Journal of Organizational Behavior, 29, 1075-99.

Kaplan, S. (2008). 'Framing contests: Strategy making under uncertainty'. Organization Science, 19, 729-52.

Kellogg, K. C. (2009). 'Operating room: Relational spaces and microinstitutional change in surgery'. American Journal of Sociology, 115, 657-711.

Kellogg, K. C. (2012). 'Making the cut: Using status-based countertactics to block social movement implementation and microinstitutional change in surgery. Organization Science, 23, $1546-70$.

Kistruck, G. M. and Beamish, P. (2010). 'The interplay of form, structure, and embeddedness in social intrapreneurship'. Entrepreneurship Theory and Practice, 34, 735-61.

Kreps, T. A. and Monin, B. (2013). “Doing well by doing good”? Ambivalent moral framing in organizations'. Research in Organizational Behavior, 31, 99-123.

Kwon, W., Clarke, I. and Wodak, R. (2014). 'Micro-level discursive strategies for constructing shared views around strategic issues in team meetings'. Journal of Management Studies, 51, $265-90$.

Lee, M. and Battilana, J. (2013). How the Zebra Got Its Stripes: Imprinting of Individuals and Hybrid Social Ventures. Working Paper 14-005, Harvard Business School, Boston, MA.

Lefsrud, L. M. and Jennings, P. D. (2014). 'Entrepreneurial storytelling: An institutional tale'. In Newbert, S. L. (Ed), Small Business in the 21st Century. Santa Barbara, CA: Praeger, 21541.

Lefsrud, L. M. and Meyer, R. E. (2012). ‘Science or science fiction? Professionals’ discursive construction of climate change'. Organization Studies, 33, 1477-506. 
Lewis, M. W., Andriopoulos, C. and Smith, W. K. (2014). 'Paradoxical leadership to enable strategic agility'. California Management Review, 56, 58-77.

Lewis, M. W. (2000). 'Exploring paradox: Toward a more comprehensive guide'. Academy of Management Review, 25, 760-76.

Ling, Y., Floyd, S. W. and Baldridge, D. C. (2005). 'Toward a model of issue-selling by subsidiary managers in multinational organizations'. Journal of International Business Studies, 36, 637-54.

Ling, Y., Baldridge, D. and Craig, J. B. (2012). 'The impact of family structure on issue selling by successor generation members in family firms'. Journal of Family Business Strategy, 3, $220-27$.

Loewenstein, J., Ocasio, W. and Jones, C. (2012). 'Vocabularies and vocabulary structure: A new approach linking categories, practices, and institutions'. Academy of Management Annals, 6, 41-86.

Mair, J. and Martí, I. (2006). 'Social entrepreneurship research: A source of explanation, prediction, and delight'. Journal of World Business, 41, 36-44.

Mair, J., Mayer, J. and Lutz, E. (2015). 'Navigating institutional plurality: Organizational governance in hybrid organizations'. Organization Studies, 36, 713-39.

Markham, S. K., Ward, S. J., Aiman-Smith, L. and Kingon, A. I. (2010). 'The valley of death as context for role theory in product innovation'. Journal of Product Innovation Management, 27, 402-17.

Martens, M. L., Jennings, J. E. and Jennings, P. D. (2007). 'Do the stories they tell get them the money they need? The role of entrepreneurial narratives in resource acquisition'. Academy of Management Journal, 50, 1107-32. 
McPherson, C. M. and Sauder, M. (2013). 'Logics in action: Managing institutional complexity in a drug court'. Administrative Science Quarterly, 58, 165-96.

Meyerson, D. E. and Scully, M. A. (1995). 'Tempered radicalism and the politics of ambivalence and change'. Organization Science, 6, 585-600.

Net Impact (2009). Making Your Impact at Work: A Practical Guide to Changing the World from Inside Any Company. San Francisco, CA.

Oliver, C. (1991). 'Strategic responses to institutional processes'. Academy of Management Review, 16, $145-79$.

Olsen, M. and Boxenbaum, E. (2009). 'Bottom-of-the-pyramid: Organizational barriers to implementation'. California Management Review, 51, 100-25.

Pache, A. C. and Santos, F. (2013). 'Inside the hybrid organization: Selective coupling as a response to competing institutional logics'. Academy of Management Journal, 56, 972-1001.

Pandza, K. (2011). 'Why and how will a group act autonomously to make an impact on the development of organizational capabilities?'. Journal of Management Studies, 48, 1015-43.

Piderit, S. K. and Ashford, S. J. (2003). 'Breaking silence: Tactical choices women managers make in speaking up about gender-equity issues'. Journal of Management Studies, 40, 1477502.

Pinkse, J. and Kolk, A. (2010). 'Challenges and trade-offs in corporate innovation for climate change'. Business Strategy and the Environment, 19, 261-72.

Porter, M. E and Kramer, M. R. (2006). 'Strategy and society: The link between competitive advantage and corporate social responsibility'. Harvard Business Review, 84, 78-92.

Prahalad, C. K. and Hart S. L. (2002). 'The fortune at the bottom of the pyramid'. Strategy and Business, 26, 1-14. 
Ren, C. R. and Guo, C. (2011). 'Middle managers' strategic role in the corporate entrepreneurial process: Attention-based effects'. Journal of Management, 37, 1586-610.

Rokeach, M. (1973). The Nature of Human Values. New York: Free Press.

Rogan, M. and Bode, C. (2014). Accenture Development Partnerships (A). Available at: http://oikos-international.org/programmes/curricula-change/cases-program/ (accessed 13 December 13 2014).

Rouleau, L. (2005). 'Micro-practices of strategic sensemaking and sensegiving: How middle managers interpret and sell change every day'. Journal of Management Studies, 42, 141341.

Rouleau, L. and Balogun, J. (2011). 'Middle managers, strategic sensemaking, and discursive competence'. Journal of Management Studies, 48, 953-83.

Santos, F. M. (2012). 'A positive theory of social entrepreneurship'. Journal of Business Ethics, $111,335-51$.

Schultz, M. and Hinings, B. (2011). 'A comment at the border between institutional and organizational culture theories'. Journal of Management Inquiry, 21, 107-08.

Scully, M., and Segal, A. (2002). 'Passion with an umbrella: Grassroots activists in the workplace'. In Lounsbury, M. and Ventresca, M. (Eds), Social Structure and Organizations Revised. Oxford: Elsevier, 125-68.

Sharma, G. and Good, D. (2013). 'The work of middle managers sensemaking and sensegiving for creating positive social change'. Journal of Applied Behavioral Science, 49, 95-122. Simpson, G. (2012). Low Cost Diagnostics for Africa. Available at: https://www.changemakers.com/intrapreneurs/entries/low-cost-diagnostics-africa (accessed 14 November 2015). 
Smets, M., Jarzabkowski, P., Burke, G. T. and Spee, P. (2015). 'Reinsurance trading in Lloyd's of London: Balancing conflicting-yet-complementary logics in practice'. Academy of Management Journal, 58, 932-70.

Smith, W. K., Gonin, M. and Besharov, M. L. (2013). 'Managing social-business tensions: A review and research agenda for social enterprise'. Business Ethics Quarterly, 23, 407-42.

Smith, W. K. and Lewis, M. W. (2011). 'Toward a theory of paradox: A dynamic equilibrium model of organizing'. Academy of Management Review, 36, 381-403.

Snow, D. A. and Benford, R. D. (1988). 'Ideology, frame resonance, and participant mobilization'. International Social Movement Research, 1, 197-218.

Snow, D. A. and Benford, R. D. (1992). 'Master frames and cycles of protest'. In Morris, A. D. and Mueller, C. M. (Eds), Frontiers to Social Movement Theory. New Haven, CT: Yale University Press, 133-55.

Snow, D., Benford, R., McCammon, H., Hewitt, L. and Fitzgerald, S. (2014). 'The emergence, development, and future of the framing perspective: $25+$ years since "frame alignment"”. Mobilization: An International Quarterly, 19, 23-46.

Snow, D. A., Rochford Jr, E. B., Worden, S. K. and Benford, R. D. (1986). 'Frame alignment processes, micromobilization, and movement participation'. American Sociological Review, 51, 464-81.

Sonenshein, S. (2006). 'Crafting social issues at work'. Academy of Management Journal, 49, $1158-72$.

Sonenshein, S. (2010). 'We're changing — or are we? Untangling the role of progressive, regressive, and stability narratives during strategic change implementation'. Academy of Management Journal, 53, 477-512. 
Sonenshein, S. (2012). 'Being a positive social change agent through issue selling'. In GoldenBiddle, K. and Dutton, J. (Eds), Using a Positive Lens to Explore Social Change and Organizations: Building a Theoretical and Research Foundation. New York: Routledge, 4970.

Sonenshein, S., DeCelles, K. and Dutton, J. (2014). 'It's not easy being green: The role of selfevaluations in explaining support of environmental issues'. Academy of Management Journal, 57, 7-37.

Sonenshein, S. (2014). 'How corporations overcome issue illegitimacy and issue equivocality to address social welfare: The role of the social change agent'. Academy of Management Review, doi: 10.5465/amr.2013.0425.

Spector, M. and Kitsuse, J. I. (1987). Constructing Social Problems. Hawthorne, NY: Aldine de Gruyter.

Spicer, A. and Sewell, G. (2010). 'From national service to global player: Transforming the organizational logic of a public broadcaster'. Journal of Management Studies, 47, 913-43.

Suchman, M. C. (1995). 'Managing legitimacy: Strategic and institutional approaches'. Academy of Management Review, 20, 571-610.

SustainAbility (2008). The Social Intrapreneur - A Field Guide for Corporate Changemakers. London, UK.

Swidler, A. (1986). 'Culture in action: Symbols and strategies'. American Sociological Review, 51, 273-86.

Tannen, D. (1985). 'Frames and schemas in interaction'. Quaderni di Semantica, 6, 326-35. 
TEDx Talks. (2013). Be the Change You Want to See in Your Company: Gib Bulloch at Tedxplainpalais. Available at: http://www.youtube.com/watch?v=5KYWJdU9Ltw (accessed 15 December 2014).

Tost, L. P. (2011). 'An integrative model of legitimacy judgments'. Academy of Management Review, 36, 686-710.

van Ginhoven, S. C. (2013). Slum Logistics: Mobile Based Addresses for Slum Areas. Available at: https://www.changemakers.com/intrapreneurs/entries/slum-logistics (accessed 14 November 2015).

Weerawardena, J. and Mort, G. S. (2012). 'Competitive strategy in socially entrepreneurial nonprofit organizations: Innovation and differentiation'. Journal of Public Policy \& Marketing, 31, 91-101.

Zald, M. N. and Berger, M. A. (1978). 'Social movements in organizations: Coup d'etat, insurgency, and mass movements'. American Journal of Sociology, 83, 823-61.

Zald, M. N. (2008). 'Epilogue: Social movements and political sociology in the analysis of organizations and markets'. Administrative Science Quarterly, 53, 568-74. 


\section{FIGURE 1}

\section{The social issue selling process in for-profit organizations}

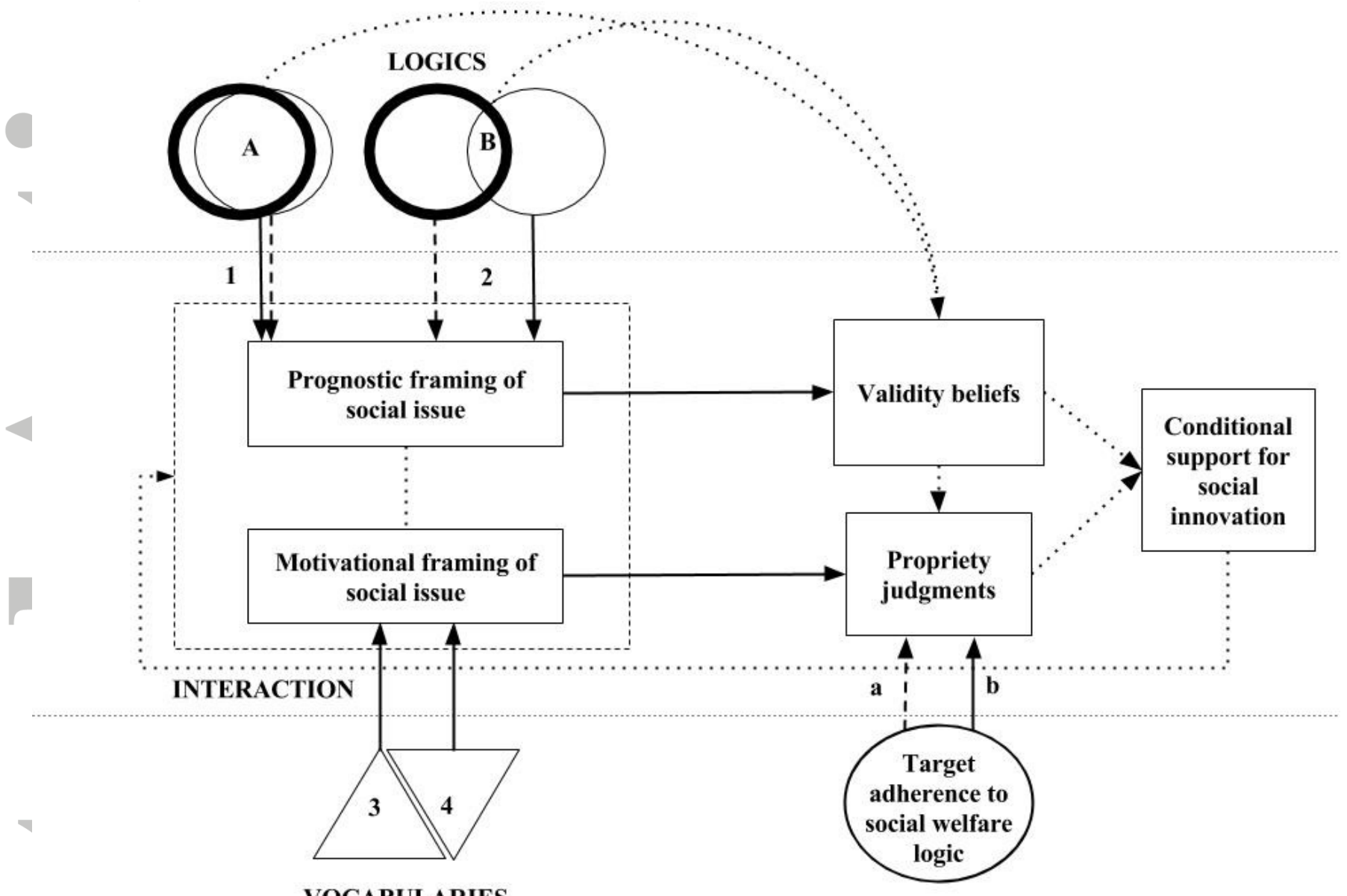

VOCABULARIES

Note

The thicker lines of the logics circles represent the centrality of the commercial logic; the degree of overlap between circles represents the compatibility between the commercial and social welfare logics. Dashed arrows indicate either subordination of one logic to the other, or low adherence. Dotted arrows represent influences on the process that are beyond the scope of our propositions.

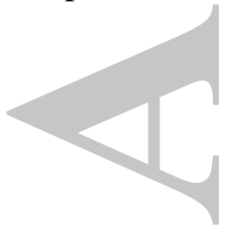


FIGURE 2

Social issue selling approaches

THE ORGANIZATION

Compatibility between commercial and social welfare logics

High (A)

Low (B)

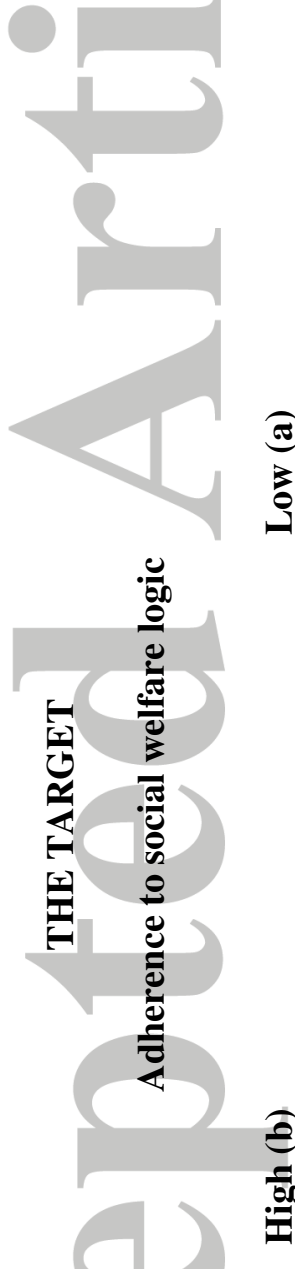

Win-win solutions (1) motivated with

restricted vocabulary (3)

Integrative solutions (2) motivated

THE COST-BENEFIT SELL

THE TROJAN HORSE SELL

Example: Environmental specialists at

Example: Kevin Thompson at IBM

with restricted vocabulary (3)

Chipco (Howard-Grenville, 2007)

(Davis and White, 2015)

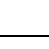

\begin{tabular}{|} 
THE ENLIGHTENED SELF- \\
INTEREST SELL
\end{tabular}

Win-win solutions (1) motivated with

Integrative solutions (2) motivated

elaborated vocabulary (4)

THE PARADOXICAL SELL

Example: Employees at Alpha

(Bansal, 2003)

with elaborated vocabulary (4)

Example: Jo da Silva at Arup

(Grayson et al., 2014)

Note

The key (letters and numbers) indicates how the selling approaches link to the propositions and the process model illustrated in Figure 1. 